\title{
Has the SARB become more effective post inflation targeting?
}

\author{
Rangan Gupta $\cdot$ Alain Kabundi $\cdot$ Mampho P. Modise
}

Received: 18 November 2009/ Accepted: 7 December 2009

(C) Springer Science+Business Media, LLC. 2010

\begin{abstract}
This paper assesses the impact of a monetary policy shock on 15 key macroeconomic variables of South Africa, in the pre- and post-inflation targeting periods. For this purpose, we use a Factor-Augmented Vector Autoregressive (FAVAR) model comprising of 107 monthly time series over two equal sub-samples of 1989:01-1997:12 and 2000:01-2008:12. The results, based on impulse response functions, are in line with economic theory and indicate no puzzling effects often observed with small-scale monetary Vector Autoregressive (VAR) models. More importantly, we find that the ability of monetary policy in affecting key macroeconomic variables, including inflation, has increased in the post-targeting period. But, majority of the effects are insignificant, which could, however, also be due to the shorter-lengths of the sub-samples relative to the number of variables used in this study, rather than depicting the inability of monetary policy to significantly affect the South African economy.
\end{abstract}

Keywords Monetary policy shock · Inflation targeting · Impulse response functions $\cdot$ FAVAR

JEL Classification C32 $\cdot$ E52 $\cdot$ E58

R. Gupta $(\bowtie) \cdot$ M. P. Modise

Department of Economics, University of Pretoria, Pretoria 0002, South Africa

e-mail: Rangan.Gupta@up.ac.za

M. P. Modise

e-mail: mamphomodise@yahoo.com

A. Kabundi

Department of Economics, University of Johannesburg, Johannesburg 2006, South Africa

e-mail: akabundi@uj.ac.za 


\section{Introduction}

The South African Reserve Bank (SARB) has been in pursuit of low inflation for nearly three decades now. Though not quite successful over the decade of 1980, the SARB made significant progress in reducing the inflation rate during the 1990s. Interestingly, the SARB pursued an implicit inflation target during the latter period. However, since the announcement made by the minister of Finance in the February of 2000 , the sole objective of the SARB has been to achieve and maintain price stability. In other words, the SARB has now adopted an explicit inflation targeting regime, whereby it aims to keep the CPIX ${ }^{1}$ inflation rate within the target band of 3-6\%, using discretionary changes in the Repurchase (Repo) rate as its main policy instrument. Against this backdrop, the paper analyzes whether or not monetary policy has become more effective, in terms of affecting the economy in general, under the official inflation targeting framework relative to the unofficial implicit inflation targeting regime.

Specifically speaking, this paper assesses the impact of monetary policy shocks on the real, monetary and financial sectors of the economy by exploiting a data-rich environment that includes 107 monthly series, such as income, interest rates, construction costs, labour market variables, stock prices, industrial production, and consumer confidence index over the sub-samples of 1989:01-1997:12 and 2000:012008:12. Note we do not consider the years of 1998 and 1999 intentionally to leave out the effects of the East Asian crisis on the South African economy. In addition, while the end date of the sample sub-periods is constrained by data availability, the starting point of the sample is to ensure that we have equal-sized sub-samples, comprising of 9 years each, in the pre (unofficial) and post inflation targeting regimes, which, however, means that we end up considering the year 1989 as well, which, historically does not fall within the implicit inflation targeting years. ${ }^{2}$

Given that we analyze 107 variables, one of the econometrically feasible frameworks that could be used is a factor-augmented vector autoregression (FAVAR) model proposed by Bernanke et al. (2005). ${ }^{3}$ Moreover, as Bernanke et al. (2005) indicates, monetary authorities analyze literally thousands of variables in their decision-making process, hence, it is aberrant for anyone, who tries to mimic actions of a central bank, to ignore this fact. Intuitively, the FAVAR approach boils down to extracting a few latent common factors from a large matrix of many economic variables, with the former maintaining the same information contained in the original data set without running into the risk of the degrees of freedom problem. ${ }^{4}$

As is well-known, since Bernanke and Blinder (1992) and Sims (1992), a considerable literature has employed vector autoregression (VAR) models to measure the effects of monetary policy innovations on macroeconomic variables.

\footnotetext{
${ }^{1}$ CPIX is defined as Consumer Price Inflation (CPI) excluding interest rates on mortgage bonds.

${ }^{2}$ Our results are, however, unaffected if we exclude the year of 1989.

${ }^{3}$ An alternative to the FAVAR model is the large-scale Bayesian VAR (LBVAR), developed recently by Banbura et al. (forthcoming). Just like the FAVAR, the LBVAR, given its estimation methodology, can also handle a data set of any size. We, however, leave the analysis involving the robustness of our obtained results based on a LBVAR, to future research.
}

${ }^{4}$ See Sect. 2 for further details. 
However, the VAR is subject to at least three major criticisms. First, the methodology can handle at most six to eight variables only. Arguably, and as indicated above, there are a large number of variables that affect the design of monetary policy, and not including them often leads to puzzling results, for example the price puzzle, that are not in line with economic theory due to the small information set (Sims 1992; Walsh 2000). Second, in the studies using VARs, the authors often arbitrarily accept specific variables as the counterparts of the theoretical constructs (for example the gross domestic product as a measure of economic activity or the first difference of the logarithm transformed consumer price index as a measure of inflation), which, in turn, may not be perfectly represented by the selected variables. In addition, studies using VARs can only obtain the impulse response functions (IRFs) for those few variables included in the model, which generally spans only a small subset of the variables that the researcher and policymakers care about. This implies that in a VAR, the IRFs are typically obtained with respect to only one variable relating to a specific sector of the economy or measuring a specific economic activity. However, one might wish to observe the responses of multiple indicators capturing a specific sector of the economy. Given its econometric construct, the FAVAR model solves all these problems.

To the best of our knowledge, this is the first study to compare the effectiveness of monetary policy across the unofficial and official inflation targeting periods on a large number of macroeconomic variables using a FAVAR approach. At this stage, it is important to mention three studies, namely Burger and Marinkov (2008) and Gupta and Uwilingiye (in press a, b), that have looked into the effectiveness of the inflation targeting regime on the level and volatility of inflation. While Gupta and Uwilingiye (in press a, b), indicates average levels and volatility of inflation would have been lower had the old regime continued, Burger and Marinkov (2008) suggest that the explicit regime has been marginally more successful in keeping inflation at lower levels, but simultaneously concede the fact that the inflation targeting system has had very limited success in keeping inflation within the official target range. As evident from the above discussion, these studies examine the impact of inflation targeting on the inflation rate only. However, a true evaluation of the framework, in other words passing a judgement on its effectiveness, requires one to take a more broad approach by looking at the impact of inflation targeting on the entire economy, above and beyond inflation. The remainder of the paper is organized as follows: Sect. 2 briefly discusses the FAVAR framework, while, Sect. 3 discusses the data. Section 4 analyzes the impulse response functions and performs the variance decomposition analysis across the regimes, with Sect. 5 devoted to conclusions and policy implications.

\section{The FAVAR model $^{5}$}

Let $Y_{t}$ be a $M \times 1$ vector of observable economic variable assumed to drive the dynamics of the economy. In the standard approach, we would proceed by estimating a structural VAR (SVAR), or other forms of multivariate time series model using

\footnotetext{
5 This paper follows the econometric framework of the FAVAR model described in Bernanke et al. (2005).
} 
data for only $Y_{t}$. In many cases, however, additional economic information that cannot be fully captured by $Y_{t}$ may be required to model appropriately the dynamics of these series. Assume that $F_{t}$ is a $K \times 1$ vector of unobserved factors, with $K$ being small, that summarizes additional important information not fully captured by $Y_{t}$. Note $F_{t}$ can also represent theoretical concepts such as price pressures, credit conditions, or even economic activity that are a combination of economic variables which cannot be represented by one particular series. Assume that the joint dynamics of $\left(F_{t}, Y_{t}\right)$ are given by the following equation:

$$
\left[\begin{array}{l}
F_{t} \\
Y_{t}
\end{array}\right]=\Phi(L)\left[\begin{array}{c}
F_{t-1} \\
Y_{t-1}
\end{array}\right]+v_{t}
$$

where $\Phi(L)$ is a conformable lag polynomial of finite order $p$ and $v_{t}$ is the error term with zero mean and a covariance matrix $Q$.

Equation (1) is a standard VAR in $\left(F_{t}, Y_{t}\right)$ and nests a standard VAR in $Y_{t}$, if the terms of $\Phi(L)$ that relate to $Y_{t}$ to $F_{t-1}$ are equal to zero. In its current form we refer to Eq. (1) as a FAVAR. Clearly the system defined by (1) helps in assessing the marginal contribution of the additional information content of $F_{t}$. Moreover, if (1) is estimated without the factors then we would obtain biased estimates of coefficients for both the VAR and the impulse responses.

However, the difficulty here is that the vector of factors $F_{t}$ is unobserved, which means that the model cannot be estimated based on standard econometric techniques, such as the ordinary least squares (OLS). The proper estimation of the model entails the use of factor analysis, as proposed by Stock and Watson (1998). For this purpose, we interpret the factors as summarizing information contained in a large panel of economic time series. Given this, we can hope to infer about the factors from these variables. Let $X_{t}$ be a $N \times 1$ vector of informational variables, where $N$ is large, such that $N \gg K+M$. Assume $X_{t}$ is related to both the observed variables $Y_{t}$ and unobserved factors $F_{t}$ as follows:

$$
X_{t}^{\prime}=\Lambda^{f} F_{t}^{\prime}+\Lambda^{y} Y_{t}^{\prime}+e_{t}^{\prime}
$$

where $\Lambda^{f}$ is a $N \times K$ matrix of factor loadings, $\Lambda^{y}$ is $N \times M$, and $e_{t}$ is a $N \times 1$ vector of the error term, which, in turn, is assumed to be weakly correlated with mean zero. In essence, $Y_{t}$ and $F_{t}$ are common forces that drive the dynamics of $X_{t}$. Note, it is not restrictive to assume in principle that $X_{t}$ is dependent only on the current values of $F_{t}$ and not its lagged value, since the factors can always be interpreted to capture arbitrary lags of some fundamental factors. Excluding the observable factors from Eq. (2), we have what Stock and Watson (1998) refer to as a dynamic factor model (DFM).

The estimation procedure consists of a two-step principal components approach proposed by Bernanke et al. (2005), which, in turn, provides a non-parametric way of uncovering the space spanned by the common components, $C_{t}=\left(F_{t}^{\prime}, Y_{t}^{\prime}\right)$. In the first step, the common components, $C_{t}$, are estimated using the first $K+M$ principal components of $X_{t}$, defined as $\hat{C}_{t}$. Note the estimation of the first-step does not use the fact that $Y_{t}$ is observed. Stock and Watson (2002) demonstrate that with a large $N$, and if the number of principal components is at least as large as the number of 
factors, the principal components can consistently recover the space spanned by both $F_{t}$ and $Y_{t}$. However, $\hat{F}_{t}$ is obtained as the part of the space covered by $\hat{C}_{t}$ not spanned by $Y_{t}$. In the second step, the FAVAR model (1) is estimated via standard methods with $F_{t}$ replaced by $\hat{F}_{t}$. As discussed by Stock and Watson (2002), this approach imposes fewer distributional assumptions, when compared to the alternative single-step Bayesian likelihood approach, and also allows for some degree of cross-correlation in the idiosyncratic error term $e_{t}$, besides being computationally simple and easy to implement. In the second-step, the two-step approach, however, implies the presence of "generated regressors", and given this uncertainty in the factor estimation, we need to implement a bootstrap procedure to obtain accurate confidence intervals. In this regard, we follow Kilian (1998).

Next, we need to discuss the identification of the model described by Eqs. (1) and (2). In other words, we need to impose restrictions necessary to identify uniquely the factors and the associated loadings. Given that, in two-step estimation method, based on principal components, the factors are obtained entirely from the observation Eq. (2), identification of the factors is standard. Formally, we can choose either to restrict loadings such that: $\Lambda^{f \prime} \Lambda^{f} / N=I$ or the factors to ensure that $F / F / T=I$. Either way we obtain the same common component $F \Lambda^{f \prime}$ and the same factor space. Following Bernanke et al. (2005), we impose the factor restriction to obtain $\hat{F}=\sqrt{T} \hat{Z}$, where the $\hat{Z}$ are the eigenvectors corresponding to the $K$ largest eigenvalues of $X X^{\prime}$, ordered in a descending fashion. This approach allows us to identify the factors against any rotations.

A separate identification issue concerns the identification of innovations in the VAR part of the model, which in our case involves the identification of the monetary policy innovations. ${ }^{6}$ This is what we discuss next. In this paper, we assume that the only observable factor is the nominal, the repurchase (Repo) rate $\left(\mathrm{REPO}_{t}\right)$, i.e., the only variable included in $Y_{t}$ is $\mathrm{REPO}_{t}$. Thus, we treat the Repo rate as a factor and interpret it as the monetary policy instrument. This can be motivated on the presumption that monetary policy has pervasive effect on the economy. It must be noted that macroeconomic data is generally subject to multiple rounds of revisions and are never free of measurement error. But the Repo rate should not suffer from measurement error issues, since this would then imply the presence of an idiosyncratic component in the monetary policy instrument. With theoretical concepts not necessarily aligned with specific variables in the data, real activity and inflation can be treated as unobserved in the empirical analysis. Also treating these variables as latent factors allows one to acknowledge the issues with real-time data. Finally, there is no evidence in the history of monetary policy of South Africa that could suggest that the SARB was controlling for any other variables, i.e., using anything else than a measure of the short-term interest rate as an instrument. ${ }^{7}$

\footnotetext{
${ }^{6}$ Note, once the factors are estimated, other identifying procedures like those of Bernanke and Mihov (1998) and Uhlig (2005) can also be applied for identifying innovations. However, as recently shown by Fry and Pagan (2007), there is no reason to believe that sign restrictions will generate better quantitative estimates of the effects of shocks than the recursive identifying scheme. Additional structure might also not be empirically supported by the data, refer to the results of the Bayesian estimation of FAVAR models by Gupta et al. (2010, in press).

7 Please refer to Ludi and Ground (2006) and Naraidoo and Gupta (2009) for further details.
} 
We order the short-term interest rate measure last and treat its innovations as monetary policy "shocks", in the standard way. This ordering imposes the identifying assumption that latent factors do not respond to monetary policy innovations within the quarter. To implement this identification scheme, as in Bernanke et al. (2005), we defined two categories of variables, namely, "slowmoving" and "fast-moving". Slow moving variables are those that do not respond contemporaneously to unanticipated monetary policy shocks. They include variables such as measures of output and production, consumption, employment, interest rates and prices. In contrast, fast moving variables respond contemporaneously to policy shocks. They mainly comprise of financial variables, such as assetprice, which are highly sensitive to contemporaneous economic shocks.

With the two-step estimation, the identification requires first controlling for the part of $\hat{C}_{t}$ that corresponds to the monetary policy measure. To achieve this, first, the "slow-moving" factors, $F_{t}^{s}$, are estimated as the principal components of the "slowmoving" variables, and then, second, the following regression,

$$
\hat{C}_{t}=b_{F^{s}} \hat{F}_{t}^{s}+b_{Y} Y_{t}+e_{t},
$$

is estimated and $\hat{F}_{t}$ obtained from $\hat{C}_{t}-\hat{b}_{Y} Y_{t}$. Note that since $\hat{F}_{t}^{s}$ and $Y_{t}$ are correlated, so are $\hat{F}_{t}$ and $Y_{t}$. Finally, the VAR in $\hat{F}_{t}$ and $Y_{t}$, is estimated and identified recursively as discussed above.

The reduced form VAR, based on Eq. (1), then has the following structural form:

$$
\Gamma(L)\left[\begin{array}{c}
\hat{F}_{t} \\
Y_{t}
\end{array}\right]=u_{t}
$$

where $\Gamma(L)$ is a conformable lag polynomial of finite order $p$ and $u_{t}$ is a vector of structural innovations. Given this, we compute the impulse response functions (IRFs) of $\hat{F}_{t}$ and $Y_{t}$ as follows:

$$
\left[\begin{array}{c}
\hat{F}_{t} \\
Y_{t}
\end{array}\right]=\Psi(L) u_{t}
$$

where $\Psi(L)$ is a lag polynomial of order $h$ and $\Psi(L)=\Gamma(L)^{-1}$. Given that $X_{t}$ is estimated by $X_{t}^{\prime}=\Lambda^{f} F_{t}^{\prime}+\Lambda^{y} Y_{t}^{\prime}+e_{t}^{\prime}$, based on Eq. (2), the IRFs of $\hat{X}_{t}$ are given by:

$$
\hat{X}_{t}^{\prime}=\left[\hat{\Lambda}^{f} \hat{\Lambda}^{y}\right]\left[\begin{array}{c}
\hat{F}_{t}^{\prime} \\
Y_{t}^{\prime}
\end{array}\right]=\left[\hat{\Lambda}^{f} \hat{\Lambda}^{y}\right] \Psi(L) u_{t}^{\prime}
$$

\section{Data}

The FAVAR estimation is based on 107 monthly data series ${ }^{8}$ of South Africa, with the data covering the real, monetary, and financial sectors. We also have intangible variables, such as confidence indices, and survey variables. The data

\footnotetext{
${ }^{8}$ Given the general lack of monthly observations for variables capturing the real sector of the economy quarterly values of household disposable income, gross domestic expenditure, private consumption by
} 
used was obtained from different data providers including the SARB, Statistics South Africa and South African Chamber of Commerce and Industry. ${ }^{9}$ All series are seasonally adjusted and were made covariance stationary when estimating the DFM. The more powerful DF-GLS test is used, instead of the more popular ADF test, to assess the degree of integration of all series. All non-stationary series are made stationary through differencing. The Schwarz information criterion (SIC) is used in selecting the appropriate lag length in such a way that no serial correction is left in the stochastic error term. Where there were doubts about the presence of a unit root, the KPSS test, with the null hypothesis of stationarity, was applied.

There are various statistical approaches in determining the number of factors in the DFM. For example, Bai and Ng (2002) developed a set of criteria to guide the selection of the number of factors in large dimensional panels. The Bai and $\mathrm{Ng}$ (2002) approach, using $I C_{p 1}$ criteria, proposed 4 factors. The Principal Component Analysis (PCA) criteria, developed by Forni et al. (2000), based on cumulative eigenvalue confirmed the choice of 4 factors, since the fifth factor was found to have an eigenvalue of 0.042 , which is less than the cut off limit of $5 \%$. So we use four factors in the estimation of a FAVAR with a lag length, $p$, equal to 1 and 2, respectively, for the pre- and post-inflation targeting periods. ${ }^{10}$ As stated earlier, to account for uncertainty in the estimation of the factors, a bootstrap technique based on Kilian (1998) is implemented. This is necessary in constructing the $90 \%$ confidence intervals of the impulse responses.

\section{Findings}

\subsection{Impulse response functions (IRFs)}

The impulse responses below compare the effect of a 100 basis point monetary policy shock on 15 key macroeconomic variables in the pre- and post-inflation targeting era. Note, the responses of these variables with their $90 \%$ confidence intervals across the regimes have been depicted in Appendices B and C of the paper. The following is the list of chosen variables:

\footnotetext{
Footnote 8 continued

households and the gross national income were converted into their monthly frequencies using interpolation methods available in Eviews.

9 Details about the data and the statistical treatment of the variables used to estimate the FAVAR are reported in Appendix A of the paper.

10 The choice of 1 lag for the pre-targeting period is based on the unanimity of Final Prediction Error (FPE) criterion, the Akaike Information Criterion (AIC), the Schwarz Information Criterion (SIC) and the Hannan-Quinn (HQ) criterion, while, the decision to use 2 lags for the post-targeting era is confirmed by Final Prediction Error (FPE) criterion, the Akaike Information Criterion (AIC) and the Hannan-Quinn (HQ) criterion. Note that when longer lag lengths were used, given the general belief (Bernanke et al., 2005) that monetary policy takes about a year to impact the economy, the impulse responses became explosive.
} 
- Total production

- Motor vehicle manufacturing

- Coincident indicator

- Private sector employment

- Non-durable goods

- Value of buildings completed

- Manufacturing sub-sector of the gross fixed capital formation by private sector

- Consumer confidence

- Inflation

- Credit to private sector

- M1 money supply

- Mortgage loans outstanding

- Allshare index

- South African cents per UK pound

- South African cents per US dollar

Based on the impulse responses reported in Figs. 1, 2 and 3 and in Appendices B and $\mathrm{C}$, we can draw the following conclusions:

(1) The impulse responses are in line with common wisdom and indicate no puzzling effects, such as the price puzzle. First of all, a monetary contraction has a negative persistent effect on real economic activity, as depicted by the behaviour of employment, consumption, capital formation, total production and the coincident indicator. Further, effect on all nominal variables is negative. Since the FAVAR model contains more variables than the standard nominal and real variables used in a small-scale monetary VAR, we can also study the effect of monetary shocks on housing starts, motor vehicles manufactured, stock prices, consumer confidence and exchange rates. The effect on the value of building plans passed is quite negligible, though the negative impact on motor vehicle manufacturing lasts for more than 2 years. Consumer confidence only starts recovering around 4 years. The effect on stock prices is negative for more than 2 years. Finally, a contractionary monetary policy is found to have improved the value of the Rand, with the effect being relatively more persistent for the Rand-UK Pound exchange rate rather than the Rand-US Dollar rate. The results highlight the fact that, with the monetary policy shock identified based on a recursive identification scheme, the four factors are sufficient to properly capture the information that Sims (1992) argued to be missing from the small-scale VARs;

(2) The effect of a monetary policy shock on the 15 variables is, in general, more pronounced in the post-inflation targeting period. The result indicates that the ability of monetary policy in affecting key macroeconomic variables has increased after the SARB's decision to target inflation;

(3) But, as can be seen from Appendices B and C, majority of the effects are insignificant. This could, however, be due to the short lengths of the subsamples relative to the number of variables used in this study. 

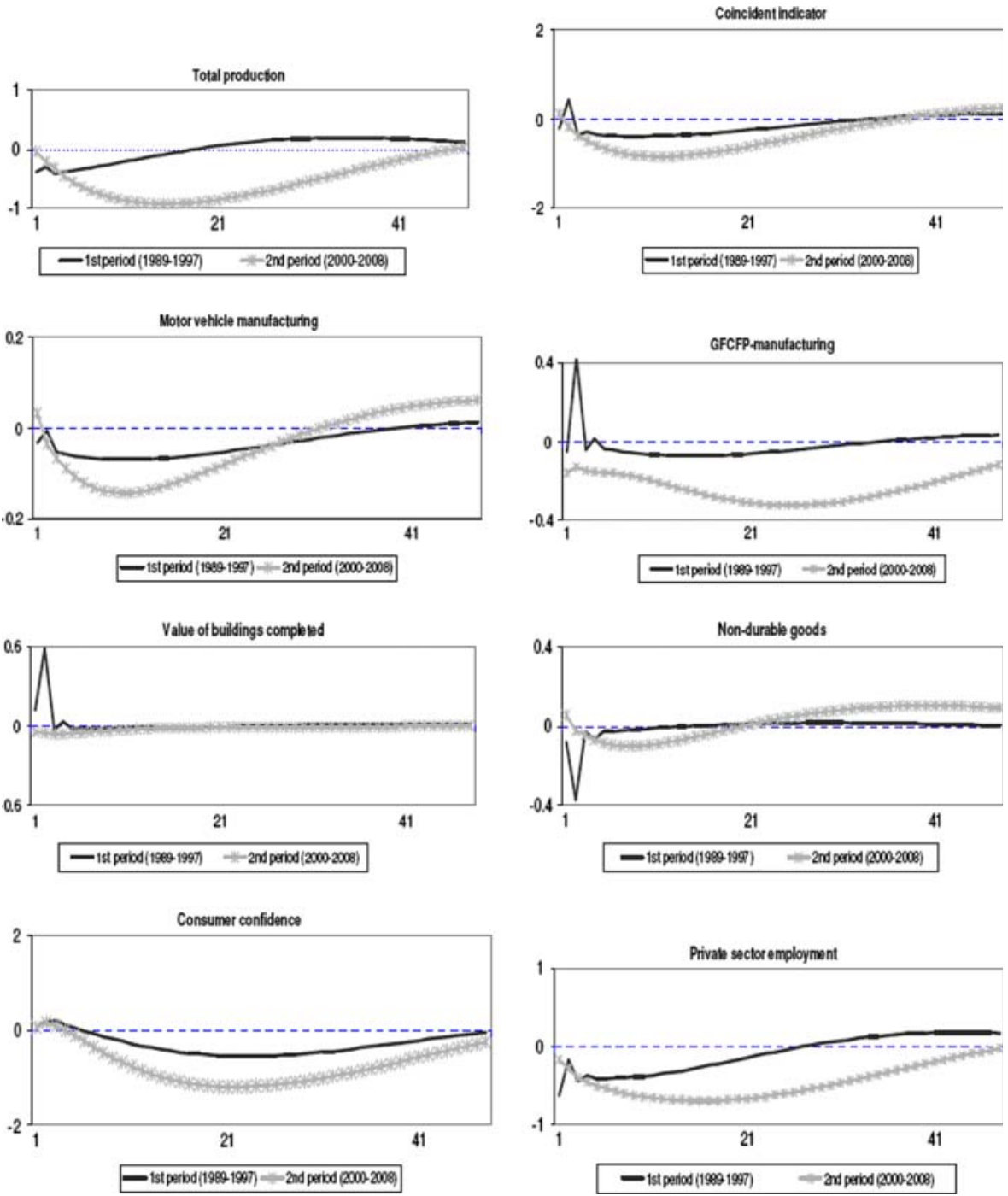

Fig. 1 Impulse response functions of selected real variables and consumer confidence following a contractionary monetary policy shock prior to and post inflation targeting

\subsection{Variance decomposition}

Other than impulse response functions, another exercise typically performed in the standard VAR context is variance decomposition, which determines, at a given horizon, the fraction of the forecasting error of a variable attributable to a particular shock. Formally, fraction variance of $Y_{t+k}-\hat{Y}_{t+k}$ due to the monetary policy shock $\left(\varepsilon_{t}^{M S}\right)$ is expressed as follows: 

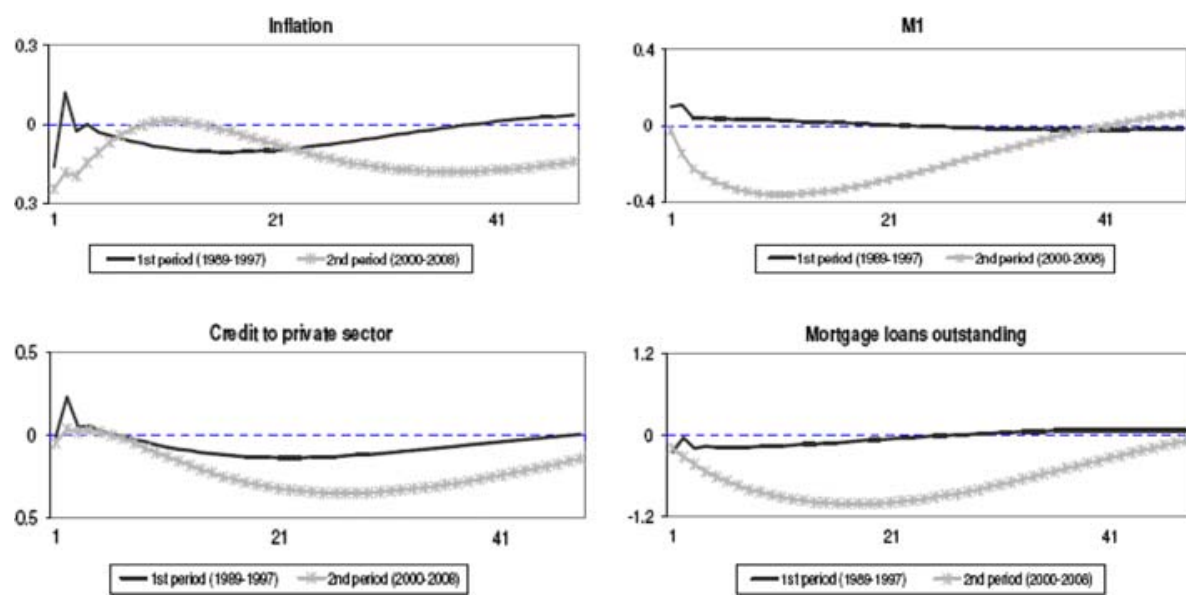

Fig. 2 Impulse response function of selected monetary variables following a contractionary monetary policy shock prior to and post inflation targeting
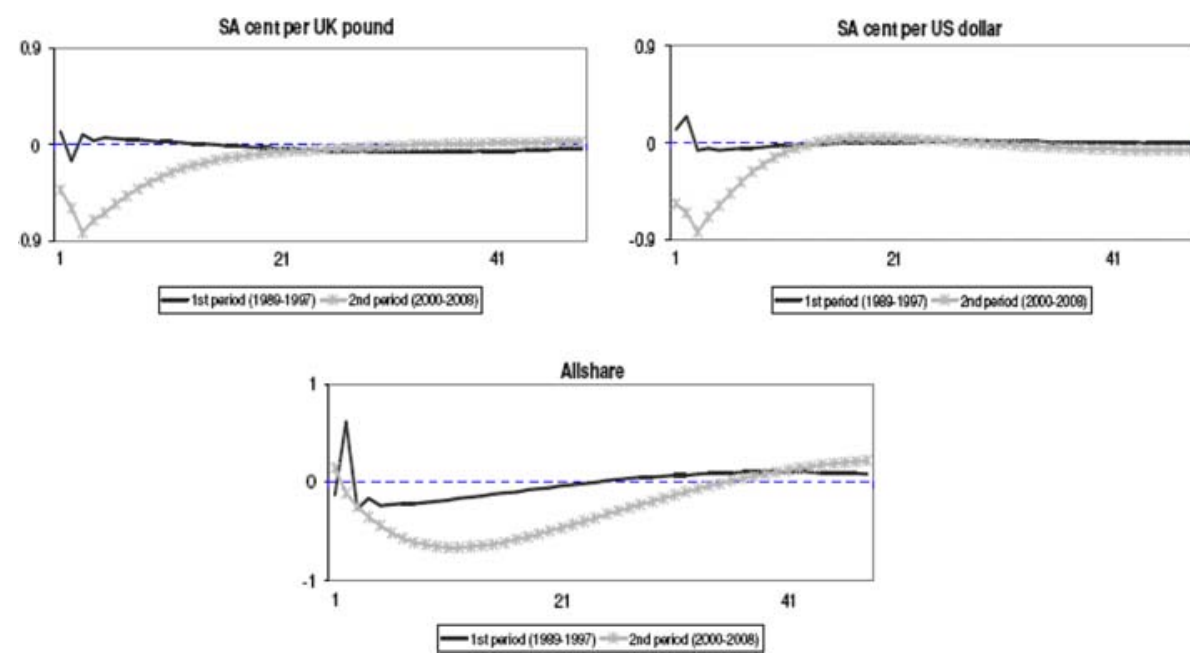

Fig. 3 Impulse response function of selected financial variables following a contractionary monetary policy shock prior to and post inflation targeting

$$
\frac{\operatorname{var}\left(\mathrm{Y}_{\mathrm{t}+\mathrm{k}}-\hat{\mathrm{Y}}_{\mathrm{t}+\mathrm{k} / \mathrm{t}} \mid \varepsilon_{\mathrm{t}}^{\mathrm{MS}}\right)}{\operatorname{var}\left(Y_{t+k}-\hat{Y}_{t+k \mid t}\right)}
$$

Note, as indicated by Eq. (2), part of the variance of the macroeconomic variables comes from their idiosyncratic component, which in part might be capturing measurement error and should not be affected by business cycle determinants. Given this, the variance decomposition of the FAVAR framework measures the relative importance of a structural shock only to the portion of the variable explained by the common factors. More precisely, this variance decomposition for $X_{i t}$ can be expressed as: 


$$
\frac{\Lambda_{i} \operatorname{var}\left(\mathrm{C}_{\mathrm{t}+\mathrm{K}}-\hat{\mathrm{C}}_{\mathrm{t}+\mathrm{K} \mid \mathrm{t}} \mid \varepsilon_{\mathrm{t}}^{\mathrm{MS}}\right) \Lambda_{\mathrm{i}}^{\prime}}{\Lambda_{i} \operatorname{var}\left(C_{t+K}-\hat{C}_{t+K \mid t}\right) \Lambda_{i}^{\prime}}
$$

where $\Lambda_{i}$ denotes the $i$ th line of $\Lambda=\left[\Lambda^{f}, \Lambda^{y}\right]$ and $\operatorname{var}\left(C_{t+K}-\hat{C}_{t+K \mid t} \mid \varepsilon_{t}^{M S}\right) /$ $\operatorname{var}\left(C_{t+K}-\hat{C}_{t+k \mid t}\right)$ is the standard VAR variance decomposition based on (1).

Table 1 reports the variance decompositions for the 15 macro economic variables used for the IRF. The second and the fourth column reports the contribution of the monetary policy shock to the variance of the forecast of the common component at the 48 month horizon for the pre- and post-inflation-targeting periods, respectively, while, columns 3 and 5 contains the $R^{2}$ of the common component for each of the 15 variables for the pre and post-targeting eras, respectively. The product of columns 2 and 3 , and 4 and 5 is equivalent to the standard variance decomposition that would be obtained from a standard VAR.

The contribution of the monetary policy shock in the pre-targeting period lies between $2.45 \%$ (inflation) and $29.78 \%$ (total production), while the contribution of the same variables ranges between $2.26 \%$ (SA cent per UK pound) and $34.61 \%$ (value of buildings completed) in the post-inflation targeting period. Clearly then, monetary policy is found to have non-trivial impact on certain key macro variables. In particular, the effect on total production, motor vehicle manufacturing, private sector employment, M1 and mortgage loans outstanding in the pre-targeting period and, total production, consumer confidence, private sector employment, value of buildings completed, gross fixed capital formation in the manufacturing sector, credit to private sector, M1 and mortgage loans outstanding in the post inflation targeting period are nearly $10 \%$ and over. More importantly, the effect of the monetary policy shock is found to be relatively stronger in the post targeting period on 10 of the 15 variables. Looking at the $R^{2}$ component, we can make the following

Table 1 Variance decomposition (VD) analysis

\begin{tabular}{lllll}
\hline Sector & 1st Period (VD) & 1st Period $\left(R^{2}\right)$ & 2nd Period $(\mathrm{VD})$ & 2nd Period $\left(R^{2}\right)$ \\
\hline Total production & 0.2978 & 0.1945 & 0.1110 & 0.5061 \\
Motor vehicle manufacturing & 0.1007 & 0.0139 & 0.0791 & 0.0135 \\
Consumer confidence & 0.0707 & 0.8578 & 0.1134 & 0.8612 \\
Coincident indicator & 0.0696 & 0.4255 & 0.0850 & 0.4493 \\
Private sector employment & 0.1669 & 0.3031 & 0.2443 & 0.2608 \\
Non-durable goods & 0.0684 & 0.0454 & 0.0533 & 0.0162 \\
Value of buildings completed & 0.0542 & 0.1246 & 0.3461 & 0.0006 \\
Inflation & 0.0245 & 0.0929 & 0.0460 & 0.0681 \\
GFCFP-manufacturing & 0.0415 & 0.1163 & 0.2219 & 0.0744 \\
Credit to private sector & 0.0560 & 0.0745 & 0.1011 & 0.0887 \\
M1 & 0.0953 & 0.0086 & 0.1403 & 0.0684 \\
Mortgage loans outstanding & 0.1700 & 0.0521 & 0.1861 & 0.5867 \\
All Share Price Index & 0.0414 & 0.3135 & 0.0780 & 0.2706 \\
SA cent per UK pound & 0.0271 & 0.0732 & 0.0226 & 0.8030 \\
SA cent per US dollar & 0.0269 & 0.0915 & 0.0243 & 0.7557 \\
\hline
\end{tabular}


observations: First, the factors explain a sizeable fraction of these variables, in particular consumer confidence $(85.78 \%)$, coincident indicator $(42.55 \%)$, and private sector employment $(30.31 \%)$ and the all share index $(31.35 \%)$ in the pretargeting era, and total production (50.61\%), consumer confidence (86.12\%), coincident indicator $(44.93 \%)$, private sector employment $(26.08 \%)$, mortgage loans outstanding $(58.67 \%)$, share price index $(27.06 \%)$, the rand pound exchange rate $(80.30 \%)$ and the rand US dollar exchange rate $(75.57 \%)$ in the post targeting period. This confirms that the FAVAR model does capture important dimensions of the business cycle. Second, the discrepancies between the variance decomposition of a standard VAR and that from the FAVAR are considerable, when one takes account of the $R^{2}$ of the common component. Finally, even though the effect of a monetary policy shock on inflation has increased in the post-targeting period, the value of the variance decompositions are one of the smallest (in fact the lowest and third lowest in the pre- and post-targeting periods, respectively), when compared to the other variables, in both the regimes.

\section{Conclusion and recommendations}

The paper analyzes whether or not monetary policy has become more effective, in terms of affecting the economy in general, under the official inflation targeting framework relative to the unofficial implicit inflation targeting regime. To make our case, we assess the impact of monetary policy shocks on the real, monetary and financial sectors of the economy by using a FAVAR framework which exploits a data-rich environment of 107 monthly series, such as income, interest rates, construction costs, labor market variables, stock prices, industrial production, and consumer confidence index over the sub-samples of 1989:01-1997:12 and 2000:012008:12. The results, based on impulse response functions, are in line with economic theory and indicate no puzzling effects often observed with small-scale monetary VAR models. More importantly, we find that the ability of monetary policy in affecting key macroeconomic variables have increased in the posttargeting period. But, majority of the effects is insignificant, which could, however, also be due to the shorter-lengths of the sub-samples relative to the number of variables used in this study, rather than depicting the inability of monetary policy to significantly affect the South African economy.

Given that South Africa targets inflation, a matter of concern is the contribution of the monetary policy shock in explaining inflation. Though, as indicated above, the effect of the monetary policy shock in stabilizing inflation is now relatively higher under the targeting regime, compared to the pre-targeting era, is not exceptionally large, though not trivial either. Whether this is the reason behind the limited success of the inflation targeting regime in keeping inflation within the official target range, is difficult to say, but is surely a possibility. This result in particular seems to tie in well with the recent proposals made by Gupta and Uwilingiye (in press a, b), of a narrower, and possibly a lower, target band to improve the SARB's credibility and cause inflation expectations to be anchored better for the Repo rate to play a stronger role in stabilizing inflation. 


\section{Appendix A}

\section{See Table 2.}

Table 2 Data description

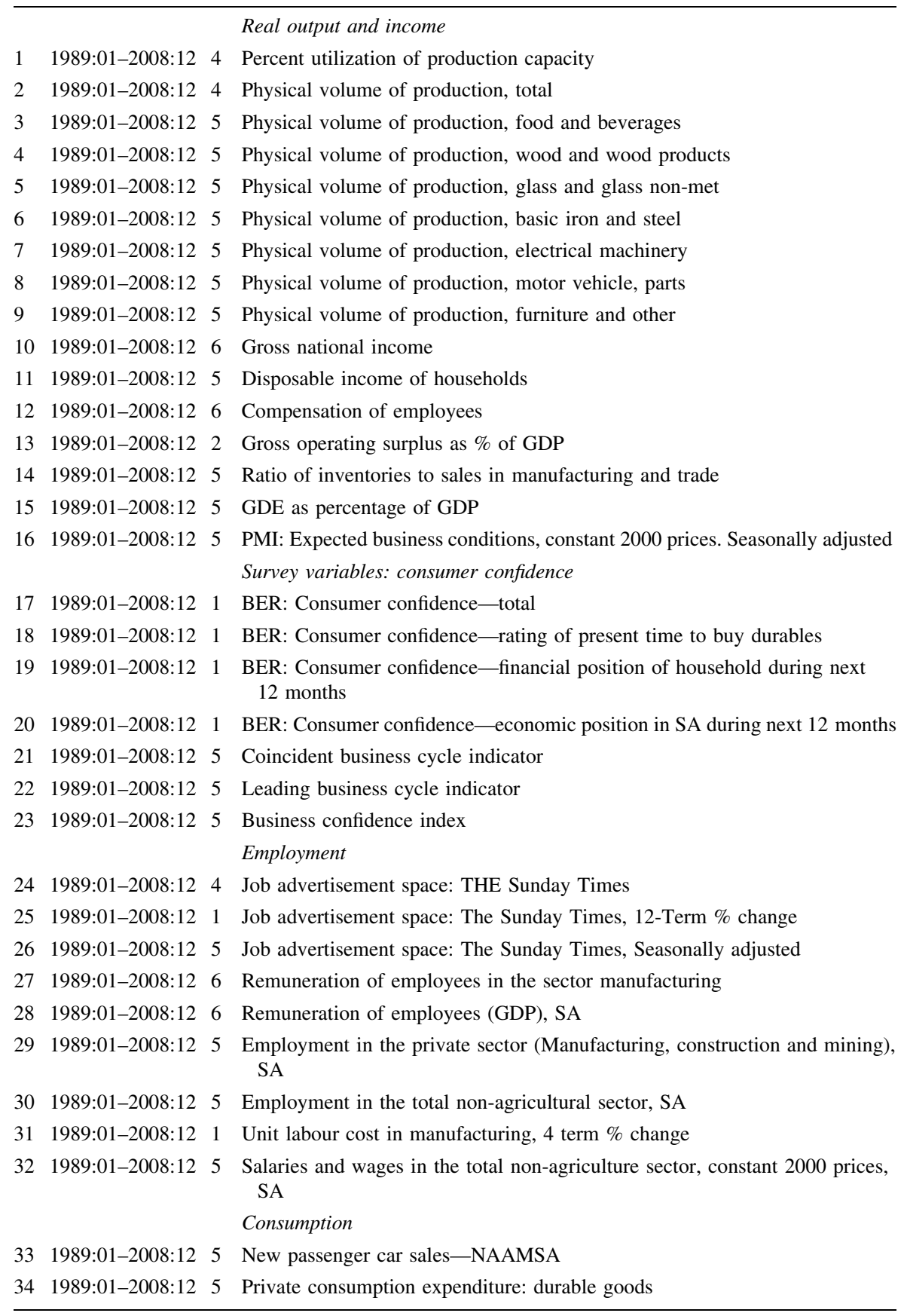


Table 2 continued

\begin{tabular}{llll}
\hline 35 & $1989: 01-2008: 12$ & 5 & Private consumption expenditure: semi-durable goods \\
36 & $1989: 01-2008: 12$ & 6 & Private consumption expenditure: non-durable goods \\
37 & $1989: 01-2008: 12$ & 5 & Private consumption expenditure: services, 2000 constant, SA \\
& & Housing related variables
\end{tabular}

38 1989:01-2008:12 5 Value of building plans passed: residential, constant 2000 prices. Index $2000=100$. Seasonally adjusted

39 1989:01-2008:12 4 Value of building plans passed: non-residential

40 1989:01-2008:12 5 Value of building plans passed: total

41 1989:01-2008:12 5 Value of building plans passed—additions and alterations: total

42 1989:01-2008:12 5 Value of building plans passed—additions and alterations: residential buildings

43 1989:01-2008:12 5 Value of building plans passed: residential buildings excluding additions and alterations

44 1989:01-2008:12 5 Value of building completed including additions and alterations: Residential buildings

45 1989:01-2008:12 5 Value of buildings completed including additions and alterations: total

46 1989:01-2008:12 5 Value of buildings completed, additions and alterations: residential buildings

47 1989:01-2008:12 5 Value of buildings completed: residential buildings, excluding additions and alterations

Real inventories

48 1989:01-2008:12 1 Change in inventories: construction (contractors)

49 1989:01-2008:12 1 Change in inventories of wholesale of private business enterprises in the sector commerce, Constant, SA

50 1989:01-2008:12 1 Change in inventories of motor trade of private business enterprises in the sector commerce

51 1989:01-2008:12 1 Change in inventories of retail trade of private business enterprises in the sector commerce

52 1989:01-2008:12 5 Book value of inventories of wholesale, retail and motor trade of private business enterprises in the sector commerce

Price indices

53 1989:01-2008:12 5 Total commodity price index

54 1989:01-2008:12 6 CPI, total (Metropolitan areas)

55 1989:01-2008:12 2 CPI annual inflation, Total (Metropolitan areas)

56 1989:01-2008:12 1 CPI annual inflation, total housing services (Metropolitan areas)

57 1989:01-2008:12 2 Domestic workers (Metropolitan areas)

58 1989:01-2008:12 2 Boarding expenses (Metropolitan areas)

59 1989:01-2008:12 1 Interest rates on mortgage loans (Metropolitan areas)

60 1989:01-2008:12 1 Public transport services (Metropolitan areas)

61 1989:01-2008:12 1 Running cost, medical and education (Metropolitan areas)

62 1989:01-2008:12 1 Medical care and health expenses (Metropolitan areas)

63 1989:01-2008:12 1 Total food excluding soft drinks (Metropolitan areas)

64 1989:01-2008:12 2 Clothing \& footwear (Metropolitan areas)

65 1989:01-2008:12 2 Furniture \& equipment (Metropolitan areas)

66 1989:01-2008:12 1 Textiles (Metropolitan areas) 
Table 2 continued

\begin{tabular}{llll}
\hline 67 & $1989: 01-2008: 12$ & 1 & Transport goods (Metropolitan areas) \\
68 & $1989: 01-2008: 12$ & 1 & Fuel \& power (Metropolitan areas) \\
69 & $1989: 01-2008: 12$ & 1 & Recreation \& entertainment (Metropolitan areas) \\
70 & $1989: 01-2008: 12$ & 6 & PPI, index 2000 = 100. Seasonally adjusted \\
71 & $1989: 01-2008: 12$ & 2 & PPI, 12-term \% change \\
& & & Investment
\end{tabular}

72 1989:01-2008:12 5 Gross domestic fixed investment: mining: residential buildings

73 1989:01-2008:12 4 Gross domestic fixed investment: mining: non-residential buildings

74 1989:01-2008:12 5 Gross domestic fixed investment: mining: construction works

75 1989:01-2008:12 5 Gross domestic fixed investment: mining: transport equipment

76 1989:01-2008:12 5 Gross domestic fixed investment: mining: other equipment

77 1989:01-2008:12 5 Gross domestic fixed investment of public corporations in non-residential buildings-manufacturing

78 1989:01-2008:12 1 Gross domestic fixed investment of public corporations in transport equipment-manufacturing

79 1989:01-2008:12 5 Gross domestic fixed investment of public corporations in other equipmentmanufacturing

80 1989:01-2008:12 5 Gross domestic fixed investment of private business enterprises in nonresidential buildings - manufacturing

81 1989:01-2008:12 5 Gross domestic fixed investment of private business enterprises in transport equipment—manufacturing

82 1989:01-2008:12 5 Gross domestic fixed investment of private business enterprises in machinery and equipment-manufacturing

Interest rates

83 1989:01-2008:12 1* Money market interest rates: bank rate and average Repo rate

84 1989:01-2008:12 $1 *$ Yield on loan stock traded on the bond exchange: government stock -0 to 3 years

85 1989:01-2008:12 1* Yield on loan stock traded on the bond exchange: government stock10 years and over

86 1989:01-2008:12 $1 *$ Yield on loan stock traded on the bond exchange: government stock-3 to 5 years

87 1989:01-2008:12 1* Predominant rate on retail deposits: 1-year fixed deposits at banks

88 1989:01-2008:12 $1 *$ Predominant rate on new mortgage loans: banks-dwelling units

89 1989:01-2008:12 1* Prime overdraft rate

90 1989:01-2008:12 1* Interest Market: banks—real rate-12-month deposit rate (Headline inflation)

91 1989:01-2008:12 1* Yield market: JSE actuaries 3-year real bond yield

Money and credit quantity aggregates

92 1989:01-2008:12 $5^{*}$ Total credit extended to the private sector, SA in millions

93 1989:01-2008:12 5* Monetary aggregates : M1, NSA in millions

94 1989:01-2008:12 $5 *$ Monetary aggregates : M3, SA in millions

95 1989:01-2008:12 $5^{*}$ Mortgage loans paid out during the period

96 1989:01-2008:12 $5^{*}$ Total mortgage loans outstanding, NSA

Exchange rate

97 1989:01-2008:12 $5 *$ SA cent per Swiss franc middle rates ( $11=100$ cents) 
Table 2 continued

\begin{tabular}{|c|c|c|c|}
\hline 98 & 1989:01-2008:12 & $5 *$ & SA cent per UK pound middle rates $(\mathrm{R} 1=100$ cents $)$ \\
\hline 99 & 1989:01-2008:12 & $5 *$ & SA cent per USA dollar middle rates ( $\mathrm{R} 1=100$ cents) \\
\hline 100 & 1989:01-2008:12 & $5^{*}$ & SA cent per Japanese yen middle rates $(\mathrm{R} 1=100$ cents $)$ \\
\hline 101 & 1989:01-2008:12 & $5 *$ & SA cent per Australian dollar middle rates $(\mathrm{R} 1=100$ cents $)$ \\
\hline 102 & 1989:01-2008:12 & $5^{*}$ & $\begin{array}{l}\text { SA cent per Canadian dollar middle rates }(\mathrm{R} 1=100 \text { cents) } \\
\text { Stock prices and other financial variables }\end{array}$ \\
\hline 103 & 1989:01-2008:12 & $5^{*}$ & JSE: all shares \\
\hline 104 & 1989:01-2008:12 & $5^{*}$ & Secondary share market: value of shares traded \\
\hline 105 & 1989:01-2008:12 & $5^{*}$ & Secondary share market: value of shares traded, Index $2000=100$ \\
\hline 106 & 1989:01-2008:12 & $1 *$ & Primary market: net issues of marketable Central Government stock \\
\hline 107 & 1989:01-2008:12 & $5 *$ & Banks and mutual banks. Change in mortgage holdings \\
\hline
\end{tabular}

The data series were obtained from different data sources including the South African Reserve Bank, Statistics South Africa and South African Chamber of Commerce and Industry. The format is similar to Bernake et al. (2004): series number; data span; transformation codes and series description as appears in the data base. The transformation codes are as follows: 1 no transformation, 2 first difference, 4 logarithm, 5 first difference of logarithm and $6 \mathrm{~s}$ difference of logarithm. An asterisk '*' after the transformation code denotes a variable assumed to be "fast-moving" in the estimation

\section{Appendix B}

See Fig. 4.
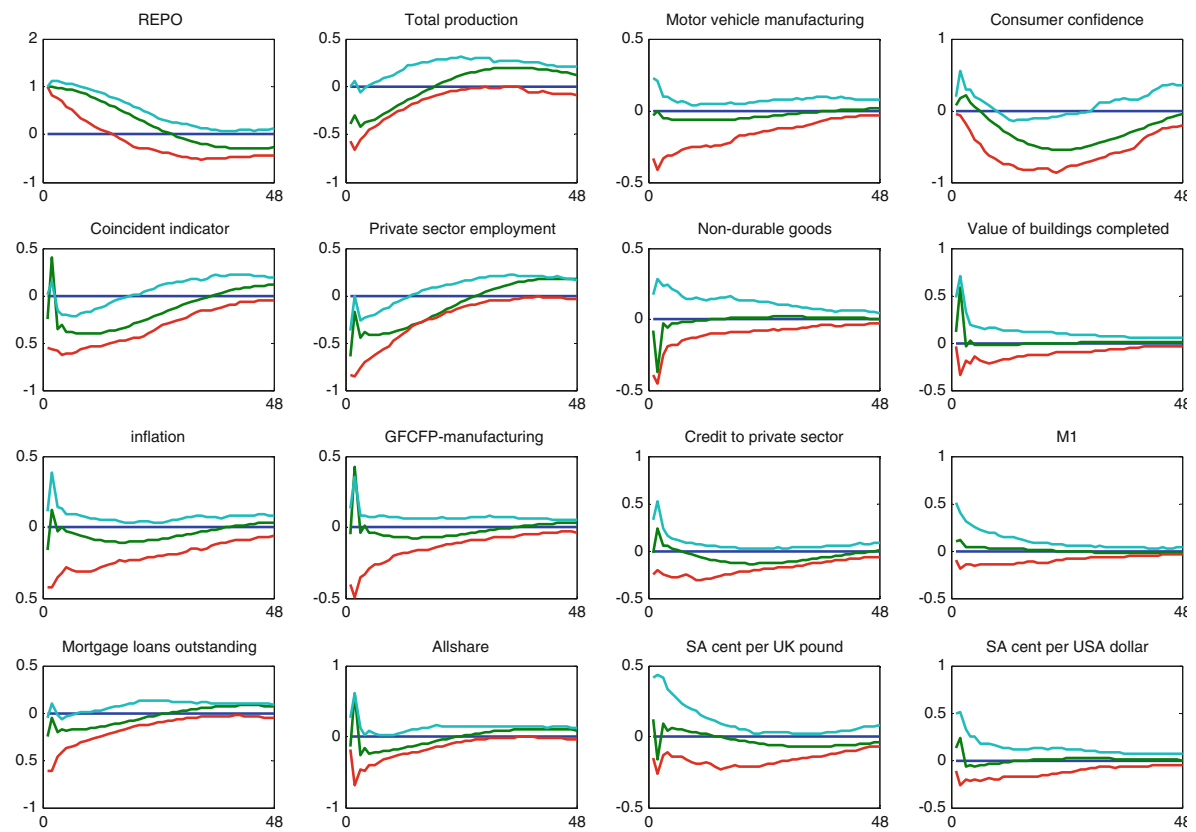

Fig. 4 Impulse response functions for the pre-inflation targeting period 


\section{Appendix C}

See Fig. 5.
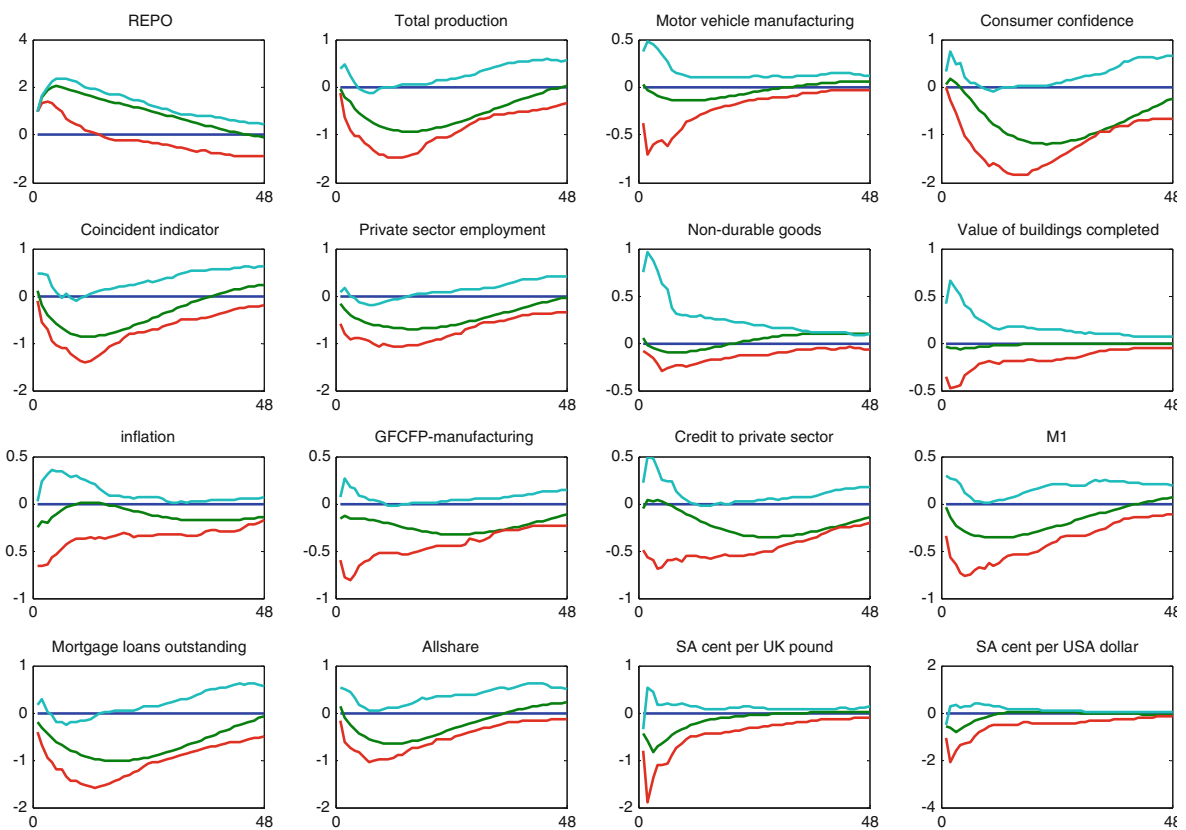

Fig. 5 Impulse response functions for the post-inflation targeting period

\section{References}

Bai J, Ng S (2002) Determining the number of factors in approximate factor models. Econometrica 70(1):191-221

Banbura M, Giannone D, Reichlin L (forthcoming) Large Bayesian VARs. Journal of Applied Econometrics

Bernanke B, Blinder A (1992) The federal fund rate and the channels of monetary transmission. Am Econ Rev 82(3):901-921

Bernanke B, Mihov I (1998) Measuring monetary policy. Q J Econ 113(3):869-902

Bernanke B, Boivin J, Eliasz P (2005) Measuring the effects of monetary policy: a factor-augmented vector autoregressive (FAVAR) approach. Q J Econ 120(1):387-422

Burger P, Marinkov M (2008) Inflation targeting and inflation performance in South Africa. TIPS working paper

Forni M, Hallin M, Lippi M, Reichlin L (2000) The generalized dynamic factor model: identification and estimation. Rev Econ Stat 82:540-554

Fry R, Pagan A (2007) Some issues in using sign restrictions for identifying structural VARs. National Central for Econometric Research working paper series no 14

Gupta R, Uwilingiye J (in press a) Comparing South African inflation volatility across monetary policy regimes: an application of Saphe cracking. Journal of Developing Areas

Gupta R, Uwilingiye J (in press b) Should the SARB have stayed time inconsistent? South African Journal of Economics 
Gupta R, Jurgilas M, Kabundi A (2010) The effect of monetary policy on real house price growth rate in South Africa: a factor augmented vector autoregression (FAVAR) approach. Econ Model 27(1):315-323

Gupta R, Jurgilas M, Kabundi A (in press) The effect of monetary policy on house price inflation: a factor augmented vector autoregression (FAVAR) approach. J Econ Stud

Kilian L (1998) Small-sample confidence intervals for impulse response functions. Rev Econ Stat $80: 218-230$

Ludi K, Ground M (2006) Investigating the bank lending channel in South Africa: a VAR approach. University of Pretoria department of economics working paper no 200604

Naraidoo R, Gupta R (2009) Modelling monetary policy in South Africa: focus on inflation targeting era using a simple learning rule. University of Pretoria department of economics working paper no. 200904

Sims C (1992) Interpreting the macroeconomic time series facts: the effects of monetary policy. Eur Econ Rev 36:975-1000

Stock J, Watson M (1998) Diffusion indexes. NBER working paper no 6702

Stock J, Watson M (2002) Macroeconomic forecasting using diffusion indexes. J Bus Eco Stat 20(2):147_ 162

Uhlig H (2005) What are the effects of monetary policy on output? Results from an agnostic identification procedure. J Monet Econ 52:381-419

Walsh C (2000) Monetary theory and policy. The MIT Press, Cambridge 